\title{
Degradation of extracellular nucleotides and their analogs in HeLa and HUVEC cell cultures ${ }^{*}$
}

\author{
Edyta Gendaszewska-Darmach ${ }^{1}$, Maria Maszewska ${ }^{1}$ Małgorzata Zakłos $^{2}$ and \\ Maria Koziołkiewicz ${ }^{1,2 凶}$ \\ ${ }^{1}$ Department of Bioorganic Chemistry, Centre of Molecular and Macromolecular Studies Polish \\ Academy of Sciences, Eódż; ${ }^{2}$ Institute of Technical Biochemistry, Technical University of Eódż, \\ Poland
}

Received: 03 October, 2003; revised: 14 November, 2003; 28 November, 2003

Key words: ectoenzymes, nucleotide pyrophosphatase, extracellular nucleotides, nucleotide analogs

\begin{abstract}
The use of nucleotides and their analogs in the pharmacological studies of nucleotide receptors (P2 class) should be preceded by detailed studies on their degradation connected with ecto-enzymes of a given cell type. In the present studies we have analyzed stability of some phosphorothioate and phosphonate analogs of ATP and ADP in the HeLa epitheloid carcinoma and endothelial HUVEC cells cultures. Our studies have revealed that ecto-nucleotide pyrophosphatase (E-NPP) is one of the main enzymes involved in the extracellular degradation of ATP and other nucleotides in the HeLa cells. On the other hand, the ecto-ATPDase is responsible for the hydrolysis of extracellular nucleotides in human endothelial cell cultures, while the E-NPP-like enzymes of the HUVEC cells are not essential to this degradation. The concerted action of the aforementioned ecto-enzymes and nucleotide pyrophosphatase, 5'-nucleotidase and adenosine deaminase present in fetal bovine serum (FBS) supplied to the
\end{abstract}

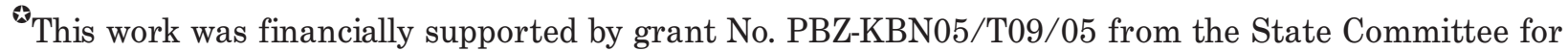
Scientific Research (KBN, Poland).

${ }^{\otimes}$ Corresponding author: Maria Koziołkiewicz, Institute of Technical Biochemistry, Technical University of Łódź, Stefanowskiego 4/10, 90-924 Łódź, Poland; phone: (48 42) 631 3497; (48 42) 681 6970; e-mail: mkoziol@bio.cbmm.lodz.pl

Abbreviations: $\mathrm{ADA}$, adenosine deaminase; $\mathrm{ADP} \beta \mathrm{S}$, adenosine $5^{\prime}-(\beta$-thio)diphosphate; $\mathrm{ATP} \gamma \mathrm{S}$, adenosine $5^{\prime}$-( $\gamma$-thio)triphosphate; dNMPS, deoxynucleoside 5 '-phosphorothioate; E-NPP, ecto-nucleotide pyrophosphatase/phosphodiesterase; E-NTPDase, ecto-nucleoside triphosphate diphosphohydrolase; FBS, fetal bovine serum; HeLa, epitheloid carcinoma cell line; HUVEC, human umbilical vein endothelial cells; MTT, 3-(4,5-dimethylthiazol-2-yl)diphenyltetrazole bromide; PC-1, plasma cell differentiation antigen; PNP, purine nucleoside phosphorylase; PPADS, pyridoxalphosphate-6-azophenyl-2',4'-disulfonic acid; P2X, ligand-gated ion channels activated by nucleotides; P2Y, G protein-coupled receptors activated by nucleotides; TCH, defined serum replacement; TEAB, triethylammonium bicarbonate; TMPS, thymidine 5 '-phosphorothioate; UMPS, uridine $5^{\prime}$-phosphorothioate.
} 
culture medium, results in partial or complete degradation of the phosphorothioate $(\operatorname{ATP} \gamma \mathrm{S})$ and phosphonate analogs of adenosine nucleotides $(\alpha, \beta$-methylene-ATP and $\beta, \gamma$-methylene-ATP) in the cell cultures. Only $\operatorname{ADP} \beta S$ appears to be resistant to these enzymes. The influence of some nucleotides and their analogs on the proliferation of the HeLa cells in presence or absence of FBS is also discussed.

Nucleosides and nucleotides can act as extracellular signaling molecules by activation of two different classes of purinergic receptors: $\mathrm{P} 1$ receptors which are responsive mainly to adenosine (subclasses: $\mathrm{A}_{1}, \mathrm{~A}_{2 \mathrm{~A}}, \mathrm{~A}_{2 \mathrm{~B}}$ and $A_{3}$ ) and $P 2$ receptors which are activated by ATP (UTP) or ADP (UDP). P2 receptors are further divided into two structural subclasses: P2X - a superfamily of ligand-gated ion channels and P2Y - a superfamily of G protein-coupled receptors (Ralevic \& Burnstock, 1998). However, not only P1 and P2 receptors are involved in signal transduction by purine and pyrimidine nucleotides. Recent studies have demonstrated that several ectoenzymes located on the extracellular side of the cell plasma membrane catalyze hydrolysis or resynthesis of ATP or other nucleotides (Zimmermann, 2000; Czajkowski \& Barańska, 2002). The products of ATP hydrolysis (ADP, AMP or adenosine) are released into the extracellular milieu where they can interact with different subclasses of receptors or enzymes to form a purinergic cascade (Williams \& Jarvis, 2000). Extracellular degradation of nucleotides is catalyzed by several cell surface-bound enzymes, which include members of the E-NTPDase family (ecto-nucleoside triphosphate diphosphohydrolase family), the E-NPP family (ecto-nucleotide pyrophosphatase/ phosphodiesterase family), alkaline phosphatases, and ecto-5'-nucleotidase (Zimmermann, 2000) (Table 1).

The enzymes of the E-NTPDase family can hydrolyze nucleoside $5^{\prime}$-triphosphates and nucleoside 5 '-diphosphates, although their preferences for the nucleotides are various. These enzymes were earlier known as ecto-apyrases, ATPases or NTPases, but their nomenclature has been recently unified by Zimmermann (2000), who has proposed the term "E-NTPDase". E-NTPDase1 hydrolyzes $\mathrm{ATP}$ and ADP at a molecular ratio of ATP/ ADP of about 1:0.5 to 1:0.9. In contrast, E-NTPDase2 has a strong preference for ATP with molecular ratio of ATP/ADP of 1:0.03 (Zimmermann, 2000).

Another class of the enzymes degrading nucleotides includes ecto-phosphodiesterase/ pyrophosphatase or PC-1 related enzymes and it has been recently re-named by Zimmermann as the E-NPP family (Goding et al., 1998; Stefan et al., 1999; Zimmermann, 1999). Members of this family possess surprisingly broad substrate specificity. Both purine and pyrimidine nucleotides can be recognized as their substrates. The NPP proteins are responsible for hydrolysis of pyrophosphate bonds of nucleoside triphosphates and phosphodiester bonds of nucleic acids. The enzymes can hydrolyze cAMP to AMP, ATP to AMP and PP, ADP to AMP and $\mathrm{P}_{\mathrm{i}}$ or $\mathrm{NAD}^{+}$to AMP and nicotinamide mononucleotide. Some members of this enzyme family can also degrade lysophospholipids (see below).

The mammalian E-NPP family includes five members but only three of them (NPP1-3) have been studied in details. NPP1 (earlier known as PC-1) has a regulatory function in bone mineralization because it catalyzes conversion of ATP into AMP and pyrophosphate (PPi), which, in turn, is an inhibitor of calcification (Goding et al., 2003). NPP2 (known also as autotaxin) was identified as a factor stimulating motility of cancer cells (Stracke $e t$ al., 1992). Recently it has been shown that NPP2 has intrinsic lysophospholipase D activity resulting in the hydrolysis of extracellular lysophosphatidylcholine (lysoPC) into lysophosphatidic acid and choline (Tokumura et al., 2002; Umezu-Goto et al., 2002). Lysophosphatidic acid (lysoPA) is known to stimu- 
late cell motility and invasion via GPCR receptors (Edg receptors) (Nobes \& Hall, 1999). In spite of the structural similarities of NPP1-3, only NPP2 has the lysophospholipase D activity, while NPP1 and NPP3 are much more active as nucleotide pyrophosphatase/phosphodiesterases. Soluble forms of NPP1 and NPP2 exist in serum and contribute to degradation of extracellular nucleotides or lysophosphatidylcholine (Frittitta et al., 1999; Goding et al., 2003).

Nucleoside 5'-monophosphates generated by the members of the E-NTPDase or E-NPP families can be converted to the corresponding nucleoside and inorganic phosphate by $5^{\prime}$-nucleotidase also known as a CD73 surface antigen. It is responsible for the formation of extracellular adenosine, but other purine and pyrimidine 5 '-mononucleotides are also dephosphorylated by this enzyme (Zimmermann, 2000).

Among the cell membrane-bound enzymes there are also ecto-kinases responsible for resynthesis of ATP and other nucleotides. Ecto-nucleoside diphosphokinase interconverting nucleoside di- and triphosphates (for example UTP and ADP to UDP and ATP) has been identified on human endothelial and astrocytoma cells as well as in human plasma (Lazarowski et al., 1997; Yegutkin et al., 2002; 2003). However, structure, properties and cellular distribution of the enzyme are not known.

The relative functional importance of the different enzymatic activities (E-NTPDases versus $\mathrm{E}-\mathrm{NPP}$ ) has not yet been defined for a given cell type and little is known how these enzymes contribute to the final pattern of extracellular nucleotide metabolism (Grobben et al., 1999). Moreover, concerted action of these enzymes can be also responsible for degradation of so called non-hydrolysable nucleotide analogs commonly used in pharmacological studies (ATP $\gamma \mathrm{S}, \alpha, \beta$-methylene-ATP, $\beta, \gamma$-methylene-ATP or $\mathrm{ADP} \beta \mathrm{S}$ ) (Grobben et al., 1999).
In this study we have analyzed stability of several phosphorothioate and phosphonate analogs of ATP and ADP in the HeLa epitheloid carcinoma cell line and human umbilical vein endothelial cells (HUVEC) cultures. We have also estimated the influence of fetal bovine serum on nucleotide-dependent HeLa cell viability.

\section{MATERIALS AND METHODS}

Chemicals. Fetal bovine serum (FBS) was obtained from Gibco BRL. Before being used in cell cultures, FBS was thermally inactivated by heating for $1 \mathrm{~h}$ at $56^{\circ} \mathrm{C}$. Endothelial cell growth factor (ECGF) was obtained from Boehringer (Mannheim, Germany). TCH (defined serum replacement for long-term culturing of primarily human anchorage-dependent and suspension cells) was obtained from ICN Biomedicals (U.S.A.). Nucleotides (ATP, ADP, UTP, UDP), nucleotide receptors antagonists (suramin and PPADS), $\alpha, \beta$-methyleneadenosine 5 '-triphosphate $(\alpha, \beta$-methyleneATP), $\quad \beta, \gamma$-methylene-adenosine-5'-triphosphate $(\beta, \gamma$-methylene-ATP), ATP $\gamma \mathrm{S}$ and $\mathrm{ADP} \beta \mathrm{S}$ were purchased from Sigma (Poland). Thymidine and uridine 5'-phosphorothioates (TMPS and UMPS) were synthesized as described previously (Koziołkiewicz et al., 2001).

Cell lines. Endothelial cells (HUVECs) were isolated from naval strings by washing of umbilical veins with $0.1 \%$ collagenase solution. The cell lines studied were maintained in RPMI 1640 medium supplemented with $10 \%$ (HeLa) or $20 \%$ (HUVEC) thermally inactivated FBS, $100 \mu \mathrm{g} / \mathrm{ml}$ streptomycin, and $100 \mathrm{IU} / \mathrm{ml}$ penicillin at $37^{\circ} \mathrm{C}$ in humidified atmosphere of $5 \% \mathrm{CO}_{2}$. In the case of the HUVECs, the medium was additionally supplemented with ECGF $(150 \mu \mathrm{g} / \mathrm{ml})$ and heparin $(90 \mu \mathrm{g} / \mathrm{ml})$. The endothelial cells were cultured in bottles covered with $1 \%$ gelatin. 
Chromatographic analysis of extracellular catabolism of adenosine nucleotides and their analogs. HeLa and HUVEC cells were incubated with $200 \mu \mathrm{M}$ nucleotide substrate for $72 \mathrm{~h}$ in RPMI 1640 culture medium containing $10 \%$ FBS (10\% TCH) or $20 \%$ FBS, respectively. For the correlation of degradation and cytotoxicity of nucleotides, these experiments were carried out under the same conditions as those done to analyze cytotoxicity (see below). In some experiments, the nucleotides or their analogs were added to the cells preincubated for 1 to $2 \mathrm{~h}$ with nucleotide receptors antagonists: suramin (added at a $200 \mu \mathrm{M}$ concentration) or PPADS (added at a $400 \mu \mathrm{M}$ concentration). At given time points $200 \mu \mathrm{l}$ aliquots were removed from the cell cultures, denaturated for $30 \mathrm{~min}$ at $95^{\circ} \mathrm{C}$, and spun down. The samples were stored at $-20^{\circ} \mathrm{C}$ prior to HPLC analysis. The incubation mixtures were analyzed by means of reversephase chromatography on $5 \mu$ Econosphere $\mathrm{C}_{18}$ column $(4.6 \times 250 \mathrm{~mm})$ (Altech) with a triethylammonium bicarbonate (TEAB) and $\mathrm{CH}_{3} \mathrm{CN}$ gradient: $0.1 \mathrm{M}$ TEAB to $12 \%$ $\mathrm{CH}_{3} \mathrm{CN} / 0.1 \mathrm{M}$ TEAB from 0 to $35 \mathrm{~min}$, then gradient $12 \% \mathrm{CH}_{3} \mathrm{CN} / 0.1 \mathrm{M}$ TEAB to $40 \%$ $\mathrm{CH}_{3} \mathrm{CN} / 0.1 \mathrm{M}$ TEAB from 35 to $38 \mathrm{~min}$. Under these conditions, products of the enzymatic degradation of ATP or ADP analogs were readily separated. Their identity was confirmed by co-injections with genuine samples of purine nucleotides, nucleosides or bases. In the control experiments the studied nucleotides and their analogs were added to RPMI medium supplemented with 10 or $20 \%$ FBS or TCH.

The influence of nucleotides and their analogs on cellular proliferation. Cells in exponential growth phase were washed in RPMI 1640 containing FBS or TCH and resuspended in this medium at a concentration of $5 \times 10^{4}$ per $200 \mu \mathrm{l}$ (HeLa) or $7 \times 10^{4}$ per $200 \mu \mathrm{l}$ (HUVECs). The nucleotides or their analogs were added to the cell cultures at time zero of each experiment without any further addition of the reagents. The number of cells was determined every $24 \mathrm{~h}$ by means of the tetrazolium salt (MTT) method (Hansen et al., 1989).

\section{RESULTS}

Phosphorothioate and phosphonate analogs of ATP or ADP are commonly used in studies on pharmacological characteristics of nucleotide receptors because they are thought to be resistant to serum and surface-located nucleotidases. However, some recent reports indicate that these nucleotide analogs are efficiently degraded by different isoforms of NTPDases, nucleotide pyrophosphatases and nucleotidases present in serum or located at cellular membrane of different cell types (Grobben et al., 1999; Czajkowski \& Barańska, 2002). In the present studies we have analyzed stability of some phosphorothioate $(\mathrm{ATP} \gamma \mathrm{S}, \mathrm{ADP} \beta \mathrm{S})$ and phosphonate ( $\alpha, \beta$-methylene-ATP and $\beta, \gamma$-methylene-ATP) analogs of adenosine nucleotides in HeLa and HUVEC cell cultures.

\section{Degradation of adenosine nucleotides in HUVEC cell cultures}

HPLC analysis demonstrated that ATP and ADP added to HUVEC cells culture were completely degraded during $24 \mathrm{~h}$ of incubation. Also their phosphorothioate analogs (ATP $\gamma \mathrm{S}$ and $\operatorname{ATP} \beta \mathrm{S}$ ) and those containing methylene bridge between two phosphorus atoms ( $\alpha, \beta$-methylene-ATP and $\beta, \gamma$-methylene-ATP) were partially degraded. ATP $\gamma \mathrm{S}$ and $\beta, \gamma$-methylene-ATP were converted directly to AMP, and then to adenosine and inosine (not shown). $\alpha, \beta$-Methylene-ATP was partially degraded with the formation of $\alpha, \beta$-methylene-ADP, which did not undergo further degradation. Only $\mathrm{ADP} \beta \mathrm{S}$ appeared to be stable during $72 \mathrm{~h}$ of incubation (Fig. 1). All the nucleotides studied, except ADP $\beta$ S, were also effectively degraded in control samples as the result of their incubation in the RPMI me- 

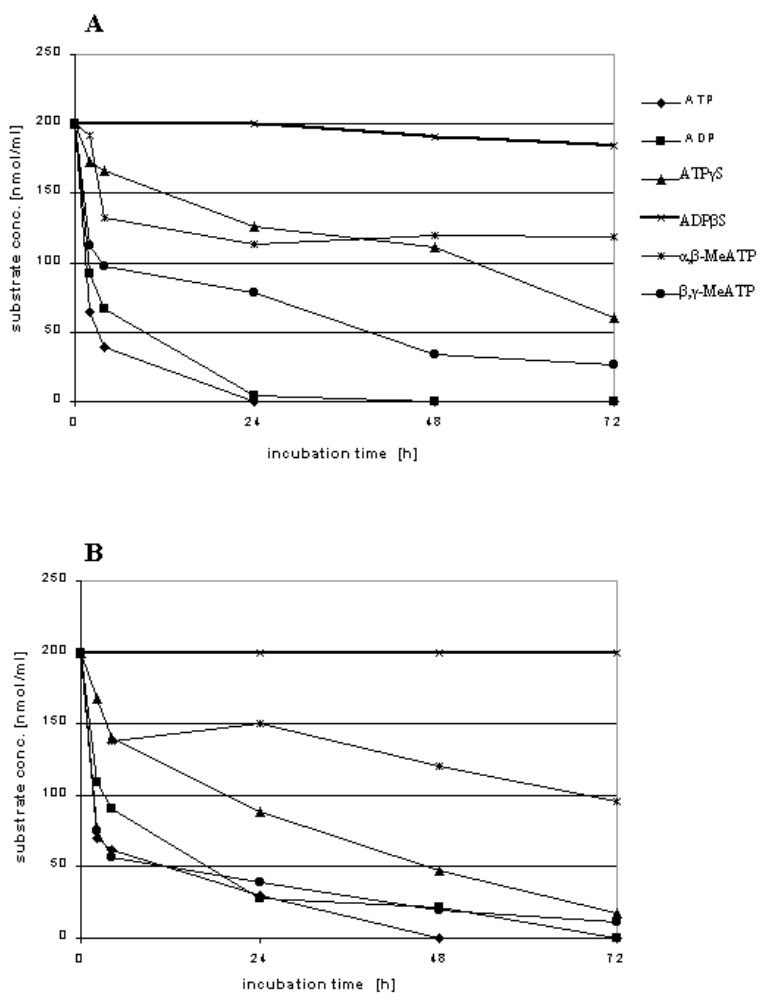

Figure 1. Time course of degradation of extracellular adenosine nucleotides in HUVEC cell culture (A) or in RPMI 1640 medium supplemented with $20 \%$ FBS (B).

The catabolism was determined by reversed phase HPLC of subsamples taken at $0,4,6,24,48$ and $72 \mathrm{~h}$ after addition of the studied nucleotides $(200 \mu \mathrm{M})$ to adhered cells (35000 per well per milliliter). The ordinate axis shows the concentration of unchanged substrate. Data points represent results of the single experiment done at triplicate.

dium supplemented with FBS. Although fetal bovine serum is routinely heat-inactivated at $56^{\circ} \mathrm{C}$ for one hour, it retains, at least, part of its enzymatic activity. In the control experiments the ATP analogs were degraded because of the following activities present in FBS: nucleotide pyrophosphatase $(\beta, \gamma$-methylene-ATP and ATP $\gamma$ S were degraded directly to AMP), 5'-nucleotidase (dephosphorylation of AMP to adenosine) and adenosine deaminase (conversion of adenosine into inosine) (Koziołkiewicz et al., 2001; Yegutkin et al., 2003).

Some of the nucleotides (e.g. ATP $\gamma \mathrm{S}$ and $\beta, \gamma$-methylene-ATP) added to the HUVEC cells appeared to be more stable than in control samples containing only FBS alone. Chromatographic analysis has shown unexpected effect - partial protection of the modified nucleotides against serum enzymes. The reason of this effect is not known, although one can assume that the binding of the modified nucleotides to membrane receptors or enzymes protects them against nucleolytic enzymes present in FBS. It is known that the ATP diphosphohydrolase (ATPDase) is the main nucleolytic ecto-enzyme of endothelial and smooth muscle cells (Picher et al., 1996). These authors have shown that some modified analogs of ATP ( $\alpha, \beta$-methylene-ATP, $\alpha, \beta$-methylene-ADP, $\beta, \gamma$-methylene-ATP, $\mathrm{ADP} \beta \mathrm{S}$ ) can bind to the ATPDase active site and reduce the activity of the enzyme to hydrolyze the natural substrates (ATP or ADP). On the other hand, the ATPDase is not able to degrade these analogs. One cannot exclude that the binding of the modified nucleotides to the membrane-bound ATPDase is responsible for their protection against serum enzymes.

It has been reported that an activity of some nucleotidases can be decreased by the use of specific inhibitors (Mateo et al., 1996). Among these inhibitors there are suramin, pyridoxalphosphate-6-azophenyl-2', 4'-disulfonic acid (PPADS) and Reactive Blue 2, which are also used as the nucleotide receptors antagonists, although nucleotide-binding sites of the nucleotidases and the nucleotide receptors are different. Trying to decrease the rate of nucleolytic degradation of the adenosine nucleotide analogs, we used suramin and PPADS as potential inhibitors of the nucleotidases present in the HUVEC cell cultures. However, suramin (used at a $200 \mu \mathrm{M}$ concentration) did not influence the rate of degradation of ATP $\gamma \mathrm{S}, \beta, \gamma$-methylene-ATP and $\alpha, \beta$-methylene-ATP. It means that suramin inhibited neither the ecto-ATPDase activity nor soluble nucleotide pyrophosphatase. Similarly, PPADS (used at a $400 \mu \mathrm{M}$ concentration) appeared ineffective as the inhibitor of fetal bovine serum and HUVEC surface-located enzymes (not shown). 
Summarizing, above results indicate that ATP and ADP added to the HUVEC cell cultures supplemented with $20 \%$ FBS are completely degraded both by serum and membrane enzymes. The activity of the serum nucleotide pyrophosphatase seems to exceed the activity of the HUVEC surface-located enzymes (mainly ATP diphosphohydrolase). Under the same conditions modified nucleotides such as ATP $\gamma \mathrm{S}, \beta, \gamma$-methylene-ATP or $\alpha, \beta$-methylene-ATP are partially degraded, while $\mathrm{ADP} \beta \mathrm{S}$ is resistant to serum nucleotide pyrophosphatase and membrane ATPDase.

We also determined the influence of ATP, $\mathrm{ADP}$ and some modified nucleotides (used at a $100 \mu \mathrm{M}$ concentration) on HUVEC cells viability. Cellular proliferation was studied for 72 hours under conditions specified above (see Materials and Methods). The strongest proliferative effect was observed for $\operatorname{ADP} \beta \mathrm{S}$, probably due to its stability (Fig. 2). The resis- nucleotide receptors) should be also taken into account.

\section{Degradation of adenosine nucleotides in HeLa cell cultures}

To avoid effects of enzymatic activity of the FBS and to compare stability of different nucleotide analogs added to the HeLa cell cultures supplemented or not with FBS, we used a serum defined replacement - TCH. HeLa cells cultured in RPMI 1640 medium supplemented with $10 \%$ TCH kept normal morphology. They also adhered to the well surface as well as under FBS conditions. The RPMI culture medium supplemented with $10 \% \mathrm{TCH}$ did not show any nucleolytic activity.

Therefore, any degradation of the nucleotides added to the HeLa cell cultures containing TCH should be attributed to ecto-enzymes

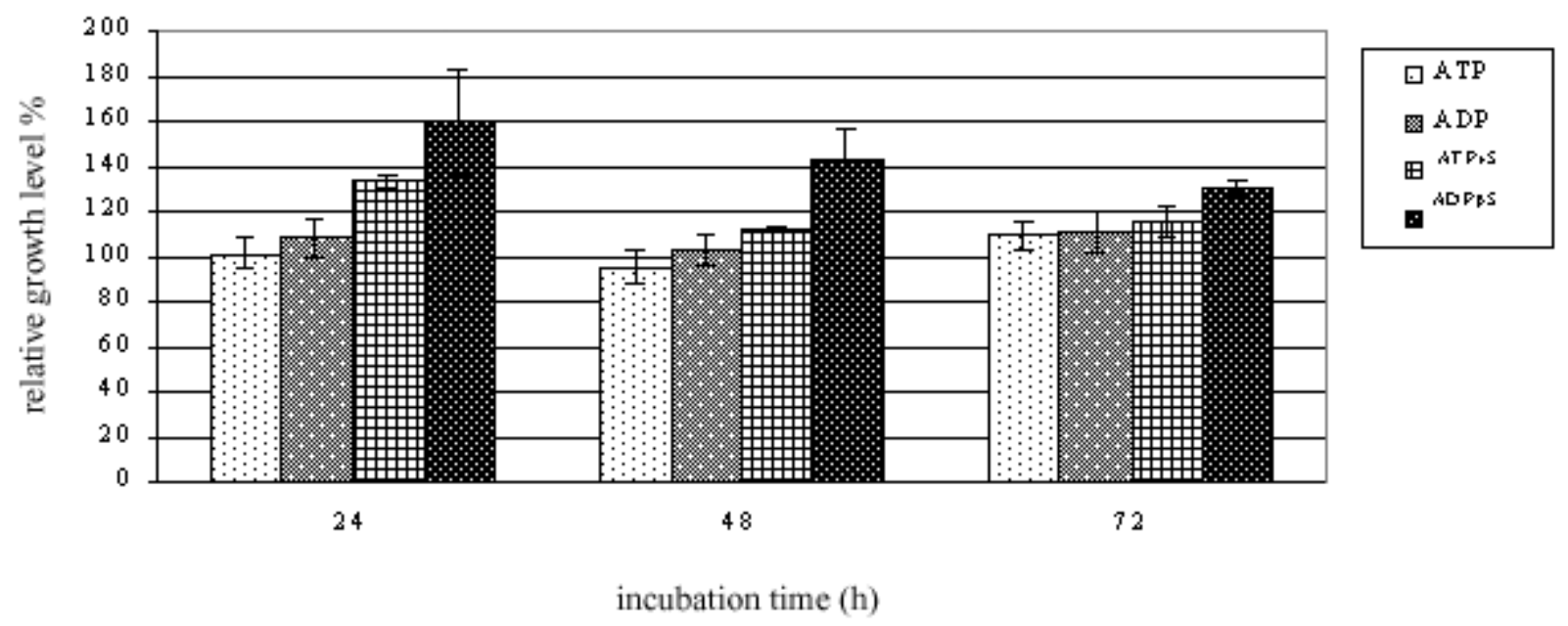

Figure 2. Relative growth level of HUVEC cells after 24, 48, 72 and $96 \mathrm{~h}$ of incubation with ATP, ATP $\gamma \mathrm{S}$, $\mathrm{ADP}$ or $\mathrm{ADP} \beta \mathrm{S}$, respectively (all used at a $100 \mu \mathrm{M}$ conc.) measured by MTT method and given in \%, where $\mathbf{1 0 0 \%}$ means the growth level of cells non treated with any nucleotide.

Data points represent means \pm S.D. from at least three independent experiments.

tance of phosphorothioate analogs of nucleotides to nucleolytic enzymes seems to be one of the more important reasons of their ability to stimulate cell proliferation, although other reasons (for example, their strong binding to present on the cell surface. HPLC analysis revealed that the main products arising during the degradation of ATP $\gamma \mathrm{S}$ and $\beta, \gamma$-methylene-ATP was adenosine monophosphate (AMP) and adenosine (not shown). After $48 \mathrm{~h}$ 
of the incubation $\beta, \gamma$-methylene-ATP was completely hydrolyzed to AMP and $\beta, \gamma$-methylene-pyrophosphate, while ATP $\gamma \mathrm{S}$ was degraded in $50 \%$ (Fig. 3). These results strongly indicate the presence of nucleotide pyrophosphatase/phosphodiesterase activity (NPP) on the HeLa cells. Under the same conditions $\alpha, \beta$-methylene-ATP was degraded by ecto-

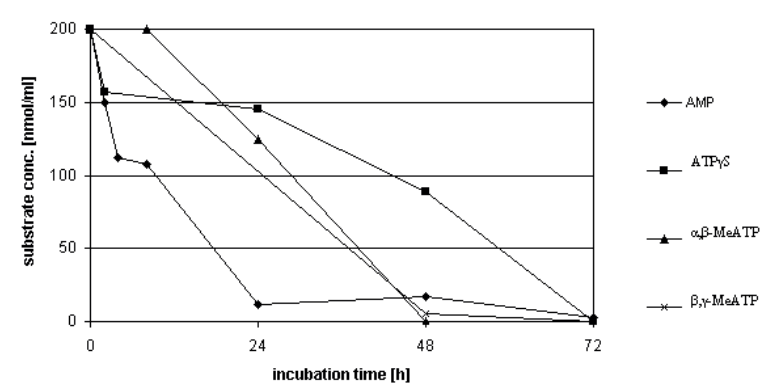

Figure 3. Degradation of adenosine nucleotides in HeLa cell culture in RPMI 1640 medium supplemented with $10 \%$ TCH.

The catabolism was determined by reversed phase HPLC of subsamples taken at 0, 4, 6, 24, 48 and $72 \mathrm{~h}$ after addition of the studied nucleotides $(200 \mu \mathrm{M})$ to adhered cells (25000 per well per milliliter). The ordinate axis shows the concentration of unchanged substrate. Data points represent results of the single experiment done at triplicate.

ATPase with the formation of $\alpha, \beta$-methylene-ADP and inorganic phosphate $\left(\mathrm{P}_{\mathrm{i}}\right)$. Further degradation of $\alpha, \beta$-methylene-ADP was not observed. Summarizing, the concerted activity of the three ectonucleolytic enzymes on HeLa cell surface: nucleotide pyrophosphatase/phosphodiesterase (NPP), ecto-ATPase and 5 -nucleotidase leads to degradation of both unmodified nucleotides and their so-called stable analogs (Fig. 3). The $5^{\prime}$-nucleotidase activity of the HeLa cells was demonstrated in our previous studies (Koziołkiewicz et al., 2001).

Unexpectedly, the RPMI supplementation with $10 \%$ TCH influenced the HeLa cells proliferation stimulated by adenosine nucleotides (Fig. 4). Adenosine nucleotides added to the HeLa cell cultures supplemented with TCH appeared to be strongly cytotoxic. After 72-h incubation of these cells with ATP, ADP, $\mathrm{ATP} \gamma \mathrm{S}$ and $\mathrm{ADP} \beta \mathrm{S}$, their viability decreased, respectively, to $30,35,45$ and $60 \%$ of the cell viability observed in control experiments carried out in the absence of the nucleotides. It means that ATP and ADP have appeared to be the most cytotoxic (Fig. 4). The same nucleotides added to the HeLa cell cultures sup-
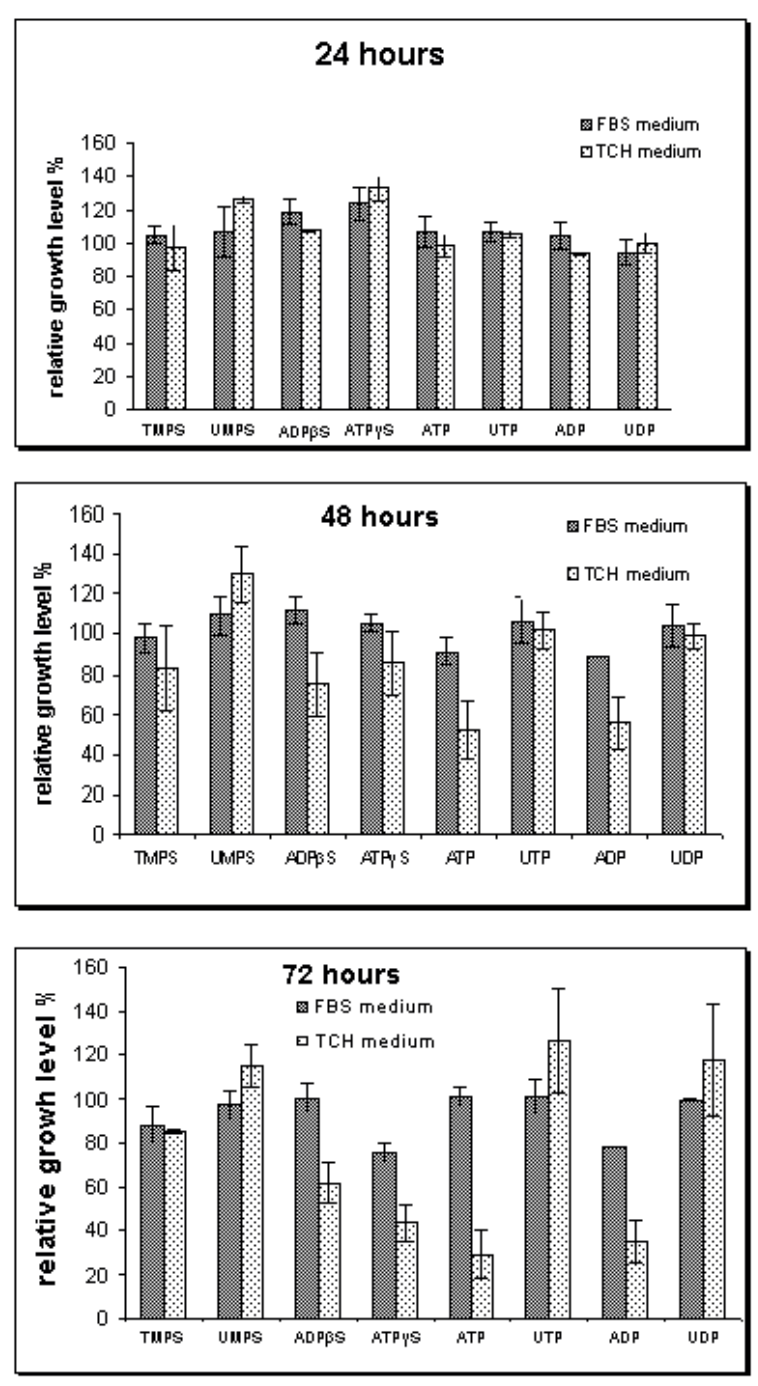

Figure 4. Relative growth level of HeLa cells incubated with adenosine or pyrimidine nucleotides in the RPMI 1640 medium containing 10\% FBS or $10 \%$ TCH after 24, 48 and $72 \mathrm{~h}$ of incubation, measured by MTT method and given in \%, where $100 \%$ means the growth level of cells non treated with any nucleotide.

Data points represent means \pm S.D. from at least three independent experiments. 
plemented with FBS did not influence the cell viabiliy. On the other hand, pyrimidine nucleotides (UTP, UDP, TMPS or UMPS) were not cytotoxic, independently on the conditions used for the HeLa cell cultures (TCH or FBS presence). We suppose that the cytotoxicity may be caused by the increasing concentration of adenosine generated from ATP, ADP or their phosphorothioate analogs by nucleotide pyrophosphatase or ectoATPase and, then, 5'-nucleotidase. Our earlier studies have shown that adenosine is

\section{DISCUSSION}

The majority of studies involving nucleotide-mediated signaling have been concerned with short-term events such as increase of $\mathrm{Ca}^{2+}$ ions or release of cAMP. However, there is increasing evidence that extracellular nucleosides and nucleotides initiate also long-term events such as cell growth, proliferation, and death (Burnstock, 2002). Studies on long-term effects (especially on nucleotide-mediated cell proliferation) often require

Table 1. The main enzymes degrading extracellular nucleotides (according to Zimmermann, 2000).

\begin{tabular}{|c|c|c|}
\hline Enzyme family & Members of the family & Reaction catalyzed \\
\hline \multirow{4}{*}{$\begin{array}{l}\text { Ecto-NTPdiphosphohydrolase } \\
\text { (E-NTPDase) }\end{array}$} & $\begin{array}{c}\text { E-NTPDase2 } \\
\text { (ecto-ATPase, CD39L1) } \\
\text { (EC 3.6.1.3) }\end{array}$ & $\begin{aligned} \mathrm{NTP} & \rightarrow \mathrm{NDP}+\mathrm{Pi} \\
(\mathrm{NDP} & \rightarrow \mathrm{NMP}+\mathrm{Pi})\end{aligned}$ \\
\hline & $\begin{array}{c}\text { E-NTPDase1 } \\
\text { (ecto-apyrase, ecto-ATPDase, CD39) } \\
\text { (EC 3.6.1.5) }\end{array}$ & $\begin{array}{l}\mathrm{NTP} \rightarrow \mathrm{NMP}+2 \mathrm{Pi} \\
\mathrm{NDP} \rightarrow \mathrm{NMP}+\mathrm{Pi}\end{array}$ \\
\hline & E-NTPDase3 (ecto-ATPDase, CD39L3) & $\begin{array}{l}\mathrm{NTP} \rightarrow \mathrm{NDP}+\mathrm{Pi} \\
\mathrm{NDP} \rightarrow \mathrm{NMP}+\mathrm{Pi}\end{array}$ \\
\hline & E-NTPDase4 (UDPase) & $\begin{array}{l}\mathrm{UTP} \rightarrow \mathrm{UDP}+\mathrm{Pi} \\
\mathrm{UDP} \rightarrow \mathrm{UMP}+\mathrm{Pi}\end{array}$ \\
\hline $\begin{array}{c}\text { Ecto-nucleotide } \\
\text { Pyrophosphatase/phosphodiesterase } \\
\text { (E-NPP) (EC 3.6.1.9) }\end{array}$ & $\begin{array}{c}\text { NPP1 (PC-1); NPP2 (autotaxin); } \\
\text { NPP3; NPP4; NPP5 }\end{array}$ & $\mathrm{NTP} \rightarrow \mathrm{NMP}+\mathrm{PPi}$ \\
\hline $\begin{array}{c}\text { Ecto-5'-nucleotidase (CD73) } \\
\text { (EC 3.1.3.5) }\end{array}$ & - & $\mathrm{NMP} \rightarrow$ Nucleoside $+\mathrm{Pi}$ \\
\hline
\end{tabular}

cytotoxic to HeLa cells, but FBS contains adenosine deaminase (ADA) and purine nucleoside phosphorylase (PNP), which very effectively convert adenosine into inosine (ADA) or to hypoxantine (ADA and PNP) (Weisman et al., 1988). Therefore, adenosine is only slightly toxic for the HeLa cells growing in the presence of FBS. However, in the RPMI medium supplemented with TCH there is no enzymes converting adenosine to non-toxic products and this is the reason of decreased viability of the HeLa cells. Although TCH is not toxic for the control cell cultures, its use followed by an addition of adenosine nucleotides can result in significant cytotoxicity. a long maintenance of cell cultures and a treatment with nucleotide ligand(s). Under these conditions extracellular nucleotides are easily hydrolyzed by membrane-bound or soluble forms of nucleotide-degrading enzymes. Recent studies of Yegutkin et al. (2003) have shown that practically all ATP in human and rabbit serum is directly converted into AMP, presumably via NPP1/PC-1-mediated pyrophosphatase reaction. Level and/or activity of the NPP-like enzymes is species-dependent. Fetal bovine serum and sheep plasma have higher nucleotide pyrophosphatase activity than human serum (Ph.D. Thesis of Dr. M. Wójcik, Centre of Molecular and Macromolecular Studies, PAS, 2000; Birk et al., 2002). 
However, mammalian serum contains not only NPP-like enzymes but also other nucleotidases (NTPDases) which can hydrolyze ATP subsequently to ADP and, then, to AMP with the release of inorganic phosphate. Circulating AMP can be degraded to adenosine and further into inosine by serum 5 '-nucleotidase and adenosine deaminase, respectively.

To avoid the enzymatic degradation of nucleotides by serum nucleotidases, cell cultures can be maintained in serum-deprived medium (Claes et al., 2001; Hou et al., 2002). However, the DNA synthesis in response of cells to nucleotide ligand usually starts 15-20 h after stimulation and the cells should be cultured for at least $72 \mathrm{~h}$. Many types of cells are not able to live in serum-deprived medium for such a long time and, therefore, this method can be used only in the studies on short-terms effects. Although the use of substitutes of serum can significantly increase the stability of the nucleotides, biological effects of the substitutes may be different than those observed in the control samples containing fetal bovine serum. As it was shown in this study, the enzymes present in serum (e.g. adenosine deaminase) are responsible for essential steps of the degradation of extracellular nucleotides and nucleosides and lack of these enzymes has influenced cell viability.

Another approach, usually applied in studies on nucleotide-mediated signaling is the use of chemically modified nucleotide analogs. There is opinion that phosphorothioate analogs of ATP (UTP) or ADP (UDP) containing a sulfur substitution at the terminal phosphates (ATP $\gamma \mathrm{S}$ or $\mathrm{ADP} \beta \mathrm{S}$ ) are stable to ectonucleotidases belonging to E-NTPDase family. Because these enzymes attack the terminal phosphorus atom to hydrolyze NTP or NDP sequentially to inorganic phosphate and to the corresponding nucleotides, the terminal phosphorothioate group of the ATP $\gamma \mathrm{S}$ or $\mathrm{ADP} \beta \mathrm{S}$ is sufficient to make these analogs non-hydrolysable by E-NTPDases. Another type of ATP or ADP analogs containing meth- ylene group between $\alpha$ and $\beta$ or $\beta$ and $\gamma$ phosphates is also thought to be resistant to these nucleotidases. Picher et al. (1996) have shown that a purified ATPDase (ATP diphosphohydrolase, EC. 3.6.1.5) from the bovine aorta is not able to dephosphorylate $\alpha, \beta$-methyleneATP, $\alpha, \beta$-methylene-ADP, $\beta, \gamma$-methyleneATP, $\beta, \gamma$-imido-ATP and $\mathrm{ADP} \beta \mathrm{S}$.

However, there are observations that some of the aforementioned compounds can be degraded by enzymes belonging to the E-NPP family (Grobben et al., 1999). It has been demonstrated that the ecto-nucleotide pyrophosphatase is the main ecto-enzyme in glioma C6 cells, $1321 \mathrm{~N} 1$ human astrocytoma and $16 \mathrm{HBH}_{14 \mathrm{o}^{-}}$human bronchial epithelial cells. In some cases NPP activity approaches or even exceeds that of the NTPDase 1 (ecto-ATPase) (Lazarowski et al., 2000). On the basis of the model of NPP mechanism action, proposed by Gijsbers et al. (2001), it is known that the enzymes can attack the $\alpha$ or $\gamma$ phosphorus atom of nucleoside $5^{\prime}$-triphosphate. During conversion of ATP directly into AMP the nucleotide pyrophosphatase attacks the $\alpha$ phosphorus atom. However, the enzyme can also act as a phosphatase and attacks the $\gamma$ phosphorus atom. It means that so called non-hydrolysable NTP analogs containing the single sulfur substitution, respectively, at the $\alpha$ or $\gamma$ position of the triphosphate chain, can be degraded by the NPP enzymes, respectively, in the $\gamma$ or $\alpha$ position. Therefore, both $\operatorname{ATP} \gamma \mathrm{S}$ and $\operatorname{ATP} \alpha \mathrm{S}$ can be degraded by the NPP enzymes with the formation of AMP or $\operatorname{ADP} \alpha \mathrm{S}$, respectively. These enzymes can also hydrolyze $\beta, \gamma$-methylene-adenosine $5^{\prime}$-triphosphate and $\beta, \gamma$-imido-adenosine $5^{\prime}$-triphosphate (Grobben et al., 1999). Our results are in agreement with above statements. Due to the preferences of nucleotide pyrophosphatase to the $\alpha$ or $\gamma$ phosphorus atoms, only adenosine- 5 -( $\beta$-thiodiphosphate) (ADP $\beta \mathrm{S})$ was not hydrolyzed in our experiments with the HUVEC cells, while other nucleotide analogs were partially or completely degraded. The enzymes responsible for the hy- 
drolysis of the nucleotides and their analogs (E-NPP and E-NTPDases) were not inhibited by suramin or PPADS although their inhibitory activity was earlier reported (Mateo et al., 1996).

Our results have revealed that ecto-nucleotide pyrophosphatase is one of the main enzymes involved in the extracellular degradation of ATP and other nucleotides by the HeLa epitheloid carcinoma cells. We have also confirmed that ecto-ATPDase is responsible for the hydrolysis of extracellular nucleotides in human endothelial cell cultures, while the NPP-like enzymes of the HUVEC cells are not essential to this degradation. Taking into account that FBS contains at least three enzymes responsible for the degradation of the nucleotides (nucleotide pyrophosphatase, $5^{\prime}$-nucleotidase and adenosine deaminase), the majority of the phosphorothioate and phosphonate analogs of adenosine nucleotides is partially or completely degraded in the cell cultures supplemented with serum. This susceptibility of ATP analogs to the degradation by serum or membrane-bound enzymes should be taken into account in the studies on nucleotide-mediated signal transduction because poorly degraded substrates of these enzymes or the resultant products can influence the cell proliferation or other so-called long-term effects in a different manner (Burnstock, 2002).

The authors thank Professor Wojciech J. Stec (the Head of the Department of Bioorganic Chemistry, Centre of Molecular and Macromolecular Studies PAS) for his encouragement and critical comments.

\section{R E F E R E N C E S}

Birk AV, Bubman D, Broekman MJ, Robertson HD, Drosopoulos JH, Marcus AJ, Szeto HH. (2002) Role of a novel soluble nucleotide phosphohydrolase from sheep plasma in inhibition of platelet reactivity: hemostasis, thrombosis and vascular biology. $J$ Lab Clin Invest.; 139: 116-24.

Burnstock G. (2002) Purinergic signaling and vascular cell proliferation and death. Arterioscler Thromb Vasc Biol.; 22: 364-73.

Claes P, Grobben B, van Kolen K, Roymans D, Slegers H. (2001) $\mathrm{P} 2 \mathrm{Y}_{\mathrm{AC}^{-}}$receptor agonists enhance the proliferation of rat $\mathrm{C} 6$ glioma cells through activation of the $\mathrm{p} 42 / 44$ mitogen-activated protein kinase. $\mathrm{Br} J$ Pharmacol.; 134: 402-8.

Czajkowski R, Barańska J. (2002) Cross-talk between the ATP and ADP nucleotide receptor signalling pathways in glioma C6 cells. Acta Biochim Polon.; 49: 877-89.

Frittitta L, Camastra S, Baratta R, Constanzo BV, D’Adamo M, Graci S, Spampinato D, Maddux BA, Vigneri R, Ferrannini E, Trischitta V. (1999) A soluble PC-1 circulates in human plasma: relationship with insulin resistance and associated abnormalities. $J$ Clin Endocrinol Metab.; 84: 3620-5.

Gijsbers R, Ceulemans H, Stalmans W, Bollen M. (2001) Structural and catalytic similarities between nucleotide pyrophosphatase/phosphodiesterase and alkaline phosphatase. J Biol Chem.; 276: 1361-8.

Goding JW, Terkeltaub R, Maurice M, Deterre P, Sali A, Belli S. (1998) Ecto-phosphodiesterase/pyrophosphatase of lymphocytes and non-lymphoid cells: structure and function of the PC-1 family. Immunol Rev.; 161: $11-26$.

Goding JW, Grobben B, Slegers H. (2003) Physiological and pathophysiological functions of the ecto-nucleotide pyrophosphatase/phosphodiesterase family. Biochim Biophys Acta.; 1638: $1-19$.

Grobben B, Anciaux K, Roymans D, Stefan C, Bollen M, Esmans EL, Slegers H. (1999) An ecto-nucleotide pyrophosphatase is one of the main enzymes involved in the extracellular metabolism of ATP in rat $\mathrm{C} 6$ glioma. J Neurochem.; 72: 826-34.

Hansen MB, Nielsen SE, Berg K. (1989) Re-examination and further development of 
a precise and rapid dye method for measuring cell growth/cell kill. J Immunol Methods.; 119: $203-10$.

Hou M, Harden K, Kuhn CM, Baldetorp B, Lazarowski E, Pendergast W, Moller S, Edvinsson L, Erlinge D. (2002) UDP acts as a growth factor for vascular smooth muscle cells by activation of $\mathrm{P}_{2} \mathrm{Y}_{6}$ receptors. Am J Physiol Heart Circ Physiol.; 282: H784-92.

Koziołkiewicz M, Gendaszewska E, Maszewska M, Stein CA, Stec WJ. (2001) The mononucleotide-dependent, nonantisense mechanism of action of phosphodiester and phosphorothioate oligonucleotides depends upon the activity of an ecto-5'-nucleotidase. Blood.; 98: 992-1005.

Lazarowski ER, Homolya L, Boucher RC, Harden TK. (1997) Identification of an ecto-nucleoside diphosphokinase and its contribution to interconversion of P2 receptor agonists. J Biol Chem.; 272: 20402-7.

Lazarowski ER, Boucher RC, Harden TK. (2000) Constitutive release of ATP and evidence for major contribution of ecto-nucleotide pyrophosphatase and nucleoside diphosphokinase to extracellular nucleotide concentration. $J$ Biol Chem.; 275: 31061-8.

Mateo J, Rotllan P, Miras-Portugal MT. (1996) Suramin - a powerful inhibitor of neural ectoadenosine polyphosphate hydrolase. $\mathrm{Br} J$ Pharmacol.; 119: 1-2.

Nobes CD, Hall A. (1999) Rho GTPases control polarity, protrusion and adhesion during cell movement. J Cell Biol.; 144: 1235-44.

Picher M, Sevigny J, D’Orleans-Juste P, Beaudoin AR. (1996) Hydrolysis of P2-purinoceptor agonists by a purified ectonucleotidase from the bovine aorta, the ATP-diphosphohydrolase. Biochem

Pharmacol.; 51: 1453-60.

Ralevic V, Burnstock G. (1998) Receptors for purines and pyrimidines. Pharmacol Rev.; 50: 413-92.

Stefan C, Gijsbers R, Stalmans W, Bollen M. (1999) Differential regulation of the expression of nucleotide pyrophosphatase and phosphodiesterase in rat liver. Biochim Biophys Acta.; 1450: 45-52.

Stracke ML, Krutzsch HC, Unsworth EJ, Arestad A, Cioce V, Schiffmann E, Liotta LA. (1992) Identification, purification, and partial sequence analysis of autotaxin, a novel motility-stimulating protein. $J$ Biol Chem.; 267: 2524-9.

Tokumura A, Majima E, Kariya Y, Tominaga K, Kogure K, Yasuda K, Fukuzawa K. (2002) Identification of human plasma lysophospholipase D, a lysophosphatidic acid-producing enzyme as autotaxin, a multi-functional phosphodiesterase. J Biol Chem.; 277: 39436-42.

Umezu-Goto M, Kishi Y, Taira A, Hama K, Dohmae N, Takio K, Yamori T, Mills GB, Inoue K, Aoki J, Arai H. (2002) Autotaxin has lysophospholipase D activity leading to tumor cell growth and motility by lysophosphatidic acid production. $J$ Cell Biol.; 158: 227-33.

Weisman GA, Lustig KD, Lane E, Huamg NN, Belzer I, Friedberg I. (1988) Growth inhibition of transformed mouse fibroblasts by adenine nucleotides occurs via generation of extracellular adenosine. $J$ Biol Chem.; 263: 12367-72.

Williams M, Jarvis MF. (2000) Purinergic and pyrimidinergic receptors as potential drug targets. Biochem Pharmacol.; 59: 1173-85.

Yegutkin GG, Henttinen T, Samburski SS, Spychala J, Jalkanen S. (2002) The evidence for two opposite, ATP-generating and ATP-consuming extracellular pathways on endothelial and lymphoid cells. Biochem J.; 367: 121-8.

Yegutkin GG, Samburski SS, Jalkanen S. (2003) Soluble purine-converting enzymes circulate in human blood and regulate extracellular ATP level via counteracting pyrophosphatase and phosphotransfer reactions. FASEB J.; 17: $1328-30$.

Zimmermann H, Braun N. (1999) Ecto-nucleotidases: molecular structure, catalytic properties and functional roles in the nervous system. Prog Brain Res.; 120: 371-85. 
Zimmermann H. (2000) Extracellular metabolism of ATP and other nucleotides.
Naunyn-Schmiedeberg's Arch Pharmacol.; 362: 299-309. 